\title{
Sistem Informasi Pengecekan Dan Pemesanan Ruangan Jarak Jauh Menggunakan Indoor Positioning System
}

\author{
H. Heru Abrianto ${ }^{1 *}$, Ririn Arissanty ${ }^{2}$ dan Irmayani ${ }^{2}$ \\ 1Universitas Tama Jagakarsa \\ Alamat Letjen TB Simatupang No. 152, Jakarta 12530 \\ 2 institut Sains dan Teknologi Nasional \\ Alamat Jl. Moh. Kahfi II, Srengseng Sawah. Jakarta 12640 \\ heruab@jagakarsa.ac.id
}

\begin{abstract}
ABSTRAK
Pada zaman moderen seperti sekarang ini aktivitas manusia sangat tinggi, dengan aktivitas yang tinggi manusia dibutuhkan sarana dan prasarana yang dapat mengakses informasi dari manapun dan kapanpun secara cepat dan akurat. IPS (Indoor Positioning System) merupakan teknologi yang mampu mendeteksi keberadaan suatu benda, atau seseorang didalam sebuah gedung jarak jauh (wireless). Dengan teknologi wireless memungkin IPS dapat dijangkau dari mana saja, semua perangkat yang sudah memiliki sarana dapat digunakan untuk melakukan validasi jarak jauh dengan menggunakan perangkat smartphone. Hal ini sangat membantu pengguna dalam mengefisienkan waktu dan pemilik dapat mengefisienkan ruangan yang tidak digunakan. Dari hasil pengujian, sistem ini mampu memberikan informasi terhadap status ruang yang kosong, serta dapat melakukan validasi dengan menggunakan kuat sinyal yang diterima oleh smartphone dari access point terdekat menggunakan metode K-NN.

Kata Kunci: Indoor Positioning System, wifi, Smartphone.
\end{abstract}

\section{Pendahuluan}

Perkembangan teknologi komunikasi dalam beberapa saat ini berkembang dan meningkat pesat, terutama pada system komunikasi nirkabel dengan mobilitas yang sangat tinggi, layanan yang cepat dan dapat diakses dari mana saja menjadi pertimbangan utama untuk mendorong pengguna meninggalkan teknologi komunikasi jaringan kabel[1]. IPS merupakan teknologi nirkabel yang dapat digunakan untuk mendeteksi keberadaan suatu benda, atau seseorang didalam sebuah gedung. IPS telah menjadi sangat populer belakangan ini. Sistem ini telah berhasil digunakan dibeberapa aplikasi pelacakan dan manajemen persediaan. Aplikasi yang sudah ada saat ini yang menggunakan layanan IPS diantaranya sistem navigasi untuk orang-orang di rumah sakit, monitoring pegawai dirumah sakit, controling ruangan, controling persediaan barang, dan lain-lain[2].

Banyaknya ruangan membuat user harus melakukan cek setiap ruangan apabila akan melakukan pertemuan. Hal ini menyebabkan terjadinya ketidakefisienan waktu untuk mengetahui ketersediaan ruangan. Untuk mengatasi permasalahan tersebut, dirancanglah suatu sistem IPS untuk pemesanan ruangan jarak jauh pada jaringan terbatas (LAN). User dapat langsung melakukan pemesanan ruangan melalui aplikasi web pemesanan ruangan menggunakan smartphone. IPS dibuat dengan memanfaatkan sinyal wifi yang akan digunakan untuk melihat status ruangan yang sedang digunakan, sudah dipesan, dan atau masih tersedia menggunakan kuat sinyal yang dikirim oleh smartphone user dari beberapa wifi yang menjangkau ruang dengan menggunakan motode K-NN (K-Nearest Neighbor)[3].

\section{Tinjauan Pustaka}

\subsection{Indoor Positioning System (IPS)}

Indoor Positioning Sytem merupakan suatu sistem yang dapat menentukan posisi seseorang di dalam suatu ruangan tertutup/gedung[4]. Sistem ini selain dapat menentukan posisi, juga dapat menentukan orientasi dan arah pergerakan seseorang. Implementasi IPS dapat dilakukan menggunakan beberapa pendekatan yang bermacammacam, umumnya menggunakan peralatan tambahan seperti sensor untrasonic, sensor infrared, RFID dan beberapa peralatan lainnya. Kombinasi sensor infrared dan ultrasonic memberikan penentuan posisi yang cukup akurat dengan tingkat kesalahan $\pm 2 \mathrm{~cm}$, untuk ruangan dengan luas $4 \mathrm{~m}^{2}$. Selain itu juga dapat dilakukan pendekatan optis menggunakan LED maupun pemanfaatan sinyal Wi-Fi[5]. 


\subsection{Wi-Fi}

Wi-Fi, adalah singkatan dari wireless fidelity, merupakan pengembangan dari istilah $\mathrm{Hi}-\mathrm{Fi}$, sebuah teknologi jaringan nirkabel yang digunakan di seluruh dunia. Wi-Fi mengacu pada sistem yang menggunakan standar 802.11, yang dikembangkan oleh Institute of Electrical and Electronics Engineers (IEEE) dan dirilis pada tahun 1997[6].

\subsection{Standar Protokol Jaringan Wireless IEEE 802.11}

(IEEE) Institute of Electrical and Electronics Engineers adalah Group dari Organisasi Insinyur yang mengatur standarisasi dalam bidang teknologi informasi. Setiap standarisasi yang diciptakan memiliki kode tersendiri. Salah satunya standarisasi di jaringan wireless yang memiliki kode 802.11[7]. Dengan adanya standar ini dimaksudkan agar setiap perangkat wireless yang berbeda tetap dapat berkomunikasi meski berbeda vendor. Berikut penjelasan mengenai jenis-jenis standar protokol jaringan wireless IEEE 802.11, yaitu:

\section{a. Wireless Tipe 802.11}

Pada Tahun 1997, IEEE menciptakan standar wireless yang pertama bekerja pada frekuensi 2,4 GHz yang dinamakan 802.11. Namun standar ini hanya mendukung bandwidth jaringan maksimal $2 \mathrm{Mbps}$, telalu kecil untuk komunikasi jaringan pada saat ini. Oleh karena itu perangkat wireless dengan standar ini tidak diproduksi lagi.

\section{b. Wireless Tipe 802.11a}

Digunakan sekitar tahun 1999, dengan kecepatan maksimum data transfer rate 54 Mbps dan bekerja pada frekuensi $5 \mathrm{GHz}$. Metode Transmisi yang digunakan adalah Orthogonal Frequency Division Multiplexing (OFDM) yang mengizinkan pentransmisian data secara pararel di dalam sub-frekuensi (resisten terhadap interferensi dengan gelombang lain)[8]. 802.11a memiliki jangkauan 35meter indoor dan 120 meter outdoor. standar 802.11a tidak kompatibel dengan $802.11 \mathrm{~b}$ atau $802.11 \mathrm{~g}$.

\section{c. Wireless Tipe 802.11b}

$802.11 \mathrm{~b}$ muncul di pasaran sekitar awal tahun 2000. Standar wireless network dengan maksimum data transfer rate 5.5 Mbps dan atau $11 \mathrm{Mbps}$ bekerja pada frekuensi $2.4 \mathrm{GHz}$. 802.11b dikenal juga dengan IEEE 802.11 HR[13]. Pada prakteknya, kecepatan maksimum dapat mencapai 5.9 Mbps pada protocol TCP dan 7.1 Mbps pada protocol UDP. Metode Transmisi yang diguanakan yakni DSSS. $802.11 \mathrm{~b}$ memiliki maksimum jangkauan 38meter indoor dan 140 meter outdoor[9].

\section{d. Wireless Tipe 802.11g}

Dipublikasikan pada bulan Juni 2003 mampu mencapai kecepatan hingga 54 Mbps pada pita frekuensi $2.4 \mathrm{GHz}$, sama seperti halnya IEEE 802.11 biasa dan IEEE 802.11 b. Tipe $802.11 \mathrm{~g}$ memiliki jangkauan maksimum 38 meter indoor dan 140 meter outdoor.

\section{e. Wireless Tipe 802.11n}

Muncul pada tahun 2009. Kecepatan dapat mencapai 600 Mbps. Tetapi setelah WiFi Alliance menguji, kecepatan hanya mencapai maksimum $450 \mathrm{Mbps}$. Bekerja pada frekuensi $2.4 \mathrm{GHz}$ dan /atau $5 \mathrm{GHz}$. Sama seperti teknologi MIMO (Multiple-Input Multiple-Output), 802.11n bekerja dengan cara meng-utilisasi banyak komponen pemancar dan penerima sinyal sehingga transmisi data dapat di lakukan pararel untuk meningkatkan nilai throughput (50-144 Mbps). 802.11n memiliki jangkauan maksimum 70meter indoor dan 250 meter outdoor. WiFi $802.11 \mathrm{n}$ ini akan diaplikasikan di device router dan adapter[14].

\section{f. Wirelsss Tipe 802.11ac}

Generasi terbaru dari standar Wifi yang populer digunakan. Memanfaatkan teknologi wireless dual band mendukung koneksi secara bersamaan pada frekuensi 2,4 GHz dan $5 \mathrm{GHz}$. Menawarkan kompabilitas dengan standar $802.11 \mathrm{~b} / \mathrm{g} / \mathrm{n}$ serta mendukung bandwidth mencapai 1300Mbps pada frekuensi $5 \mathrm{GHz}$ ditambah $450 \mathrm{Mbps}$ pada frekuensi $2,4 \mathrm{GHz}$.

\subsection{IP (Internet Protocol)}

IP address adalah alamat identifikasi komputer/host yang berada didalam jaringan. Dengan adanya IP address maka data yang dikirimkan oleh komputer pengirim dapat dikirimkan lewat protokol TCP/IP hingga sampai ke komputer yang dituju[10].Setiap komputer memiliki IP address yang unik sehingga dua komputer yang berbeda tidak boleh memiliki IP address yang sama dalam satu jaringan. IP address yang dinyatakan dalam struktur bilangan biner terdiri atas 32 bit.

\section{Metode Penelitian.}

\subsection{Algoritma K-Nearest Neighbor (KNN)}

Algoritma K-Nearest Neighbor (KNN) adalah sebuah metode untuk melakukan klasifikasi terhadap objek berdasarkan data pembelajaran yang jaraknya paling dekat dengan objek tersebut[11]. 
Adapun algoritma K-NN ditunjukan oleh diagram alur pada gambar.1

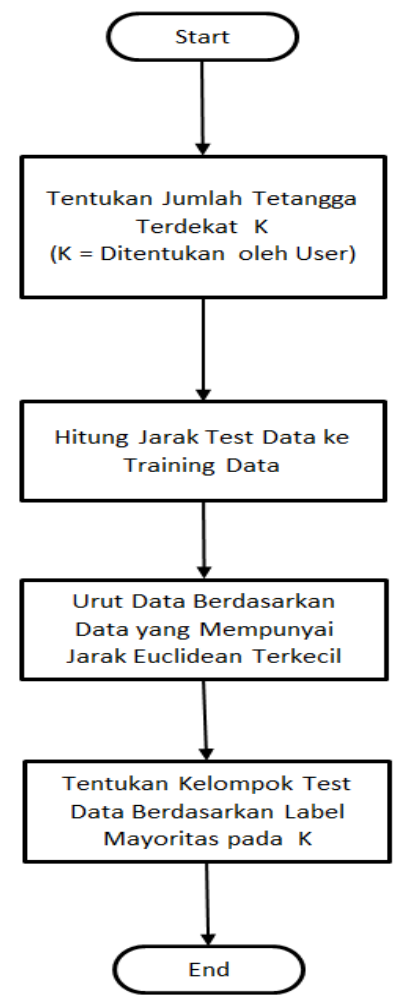

Gambar 1 Algoritma K-NN

Proses pengambilan sinyal K terdekat menggunakan metode K-NN dapat juga dilihat pada gambar 2.

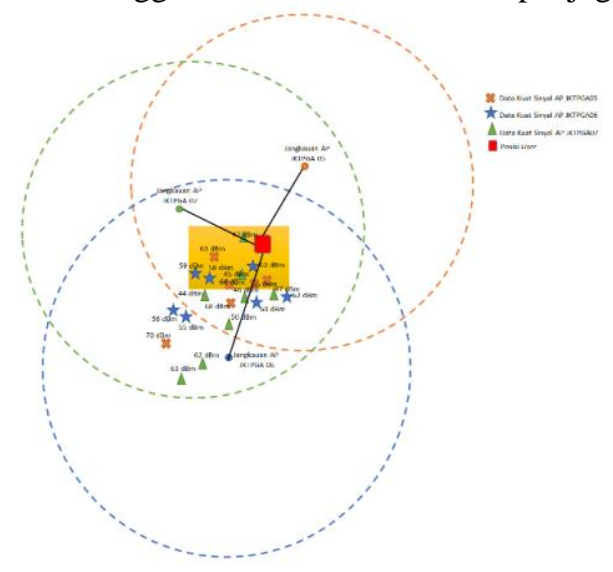

Gambar 2. Proses Pengambilan Sinyal K Terdekat

Access point mengirimkan informasi kuat sinyal yang diterima oleh smartphone user ke access point controller. Access point controller akan melakukan validasi dengan menggambil $6 \mathrm{~K}$ kuat sinyal terbesar yang diterima dari access point controller dari posisi user saat itu[12]. Klasifikasi kuat sinyal yang dipancarkan oleh access point dapat dilihat pada Tabel .1, .2 dan 3 . 
Tabel 1. Kuat Sinyal pada Access Point JKTPGA05

\begin{tabular}{|c|l|}
\hline $\begin{array}{c}\text { Kuat Sinyal } \\
(\text { dBm })\end{array}$ & \multicolumn{1}{c|}{ Keterangan } \\
\hline 63 & Ruang 2-04 \\
\hline 64 & Ruang 2-04 \\
\hline 65 & Ruang 2-04 \\
\hline 66 & Ruang 2-04 \\
\hline 68 & Bukan Ruang 2-04 \\
\hline 70 & Bukan Ruang 2-04 \\
\hline
\end{tabular}

Tabel 2 Kuat Sinyal pada Access Point JKTPGA06

\begin{tabular}{|c|l|}
\hline $\begin{array}{c}\text { Kuat Sinyal } \\
(\mathbf{d B m})\end{array}$ & \multicolumn{1}{|c|}{ Keterangan } \\
\hline 55 & Bukan Ruang 2-04 \\
\hline 56 & Bukan Ruang 2-04 \\
\hline 58 & Bukan Ruang 2-04 \\
\hline 59 & Bukan Ruang 2-04 \\
\hline 60 & Ruang 2-04 \\
\hline 62 & Ruang 2-04 \\
\hline
\end{tabular}

Tabel. 3 Kuat Sinyal pada Access Point JKTPGA07

\begin{tabular}{|c|c|}
\hline $\begin{array}{c}\text { Kuat Sinyal } \\
(\text { dBm })\end{array}$ & \multicolumn{1}{|c|}{ Keterangan } \\
\hline 42 & Ruang 2-04 \\
\hline 44 & Bukan Ruang 2-04 \\
\hline 45 & Ruang 2-04 \\
\hline 46 & Bukan Ruang 2-04 \\
\hline 47 & Bukan Ruang 2-04 \\
\hline 50 & Bukan Ruang 2-04 \\
\hline 62 & Bukan Ruang 2-04 \\
\hline 63 & Bukan Ruang 2-04 \\
\hline
\end{tabular}

Pada gambar 3, $6 \mathrm{~K}$ kuat sinyal paling besar yang diterima oleh smartphone user pada posisi yang ditunjukan oleh tanda kotak warna merah yaitu kuat sinyal $-42 \mathrm{dBm}$, dan $-45 \mathrm{dBm}$ dari access point JKTPGA07, $-63 \mathrm{dBm}$ dari access point JKTPGA06, $-64 \mathrm{dBm},-65 \mathrm{dBm}$, dan $-66 \mathrm{dBm}$ dari access point JKTPGA05.

3.2 Topologi Jaringan

Gambar 3 merupakan topologi jaringan untuk sistem ketersediaan ruangan. Pada topologi tersebut terdapat satu buah router, satu buah switch manageable sebagai device untuk menghubungkan Web server, DNS dan DHCP server, Zone Director, dan access point agar dapat saling berkomunikasi. 


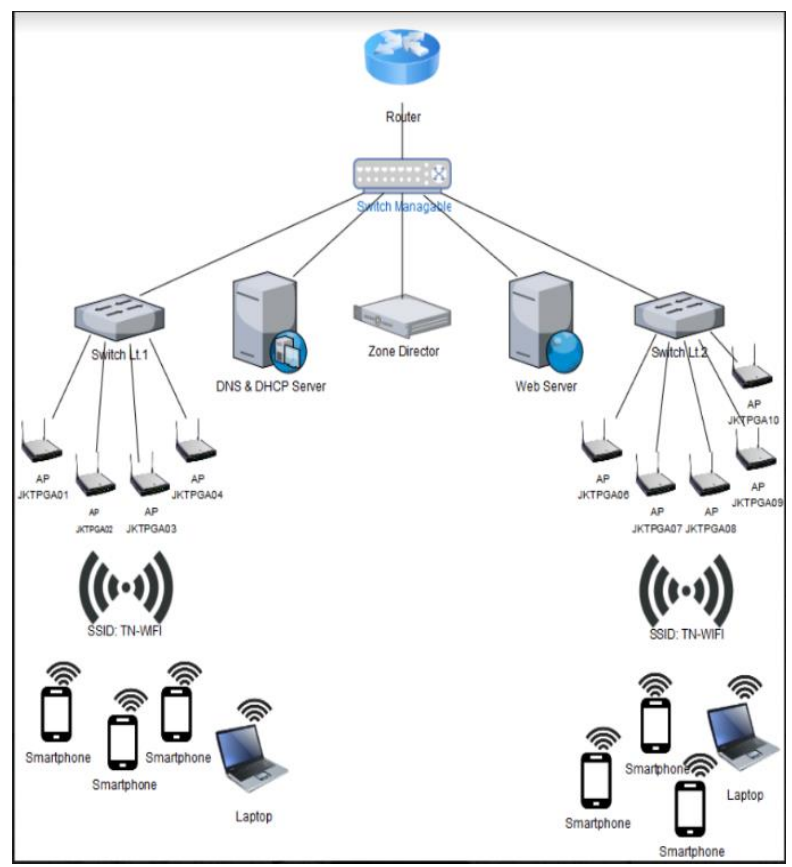

Gambar 3 Topologi Jaringan Sistem Pemesanan

Satu buah Web server untuk menyimpan data dan aplikasi ruangan, satu buah DNS dan DHCP server sebagai server untuk menyimpan dan memberikan IP dan name system ke semua device. dua buah Zone Director (Access Point Controller), dan dua buah switch yang masing-masing mencakup untuk daerah pada lantai 1 (satu) dan lantai (2), pada lantai 1 (satu) terdapat 4 (empat) access point untuk mencakup semua area yang ada pada lantai 1 . Dilantai 2 (dua) terdapat 5 (lima) access point untuk mencakup semua area yang ada pada dilantai 2 (dua). User staff melakukan konektivitas ke SSID TN-WiFi menggunakan smartphone atau notebook untuk melakukan pemesanan ruangan. Selanjunya pemesanan ruangan dapat dilakukan dengan cara membuka browser chrome, atau mozilla firefox kemudian ketikan url atau DNS traknus.roombooking pada browser chorme atau modzilla firefox, user staff memasukan nama peserta pertemuan lainnya yang akan bergabung. Setelah ruangan selesai dipesan, data peserta pertemuan yang sudah didaftarkan tersimpan di server Smartphone user terkoneksi ke wifi melalui access point client terdekat yang mencakup area dimana smartphone user berada dengan SSID TN-WiFi. Kemudian, access point yang menerima sinyal akan mengirimkan kuat sinyal yang diterima dari smartphone user ke access point controller, lalu access point controller melakukan sinkronisasi data kuat sinyal dengan yang ada di form pemesanan ruangan pada web server. Selanjutnya web server mengirimkan informasi data ke aplikasi ruangan (room booking), untuk kemudian dilakukan perubahan status terhadap ruangan

\subsection{Diagram Alur Sistem}

Pada saat user masuk ke ruangan yang sudah dipesan melalui aplikasi form pemesanan ruangan, sistem melakukan validasi melalui kuat sinyal yang diterima oleh smartphone user dari access point yang jakauannya paling dekat dengan lokasi ruangan. Selanjutnya access point mengirimkan kuat sinyal dari smartphone user ke access point controller yang kemudian dilakukan sikronisasi data oleh access point controller, antara MAC address user pada form pemesanan dengan MAC address user pada ruangan. Apabila dalam waktu lebih dari 30 menit user tidak masuk ke dalam ruangan yang sudah dipesan, Sistem akan otomatis mengubah status ruangan menjadi available.

Pada aplikasi room booking, terdapat tiga indikasi status untuk status ruangan, yaitu available, booked, dan nonavailable. Status available diberikan utnuk ruangan yang masih tersedia, status booked diberikan untuk ruangan yang sudah dipesan oleh user, dan status nonavailable diberikan untuk ruangan yang sedang digunakan oleh user. 


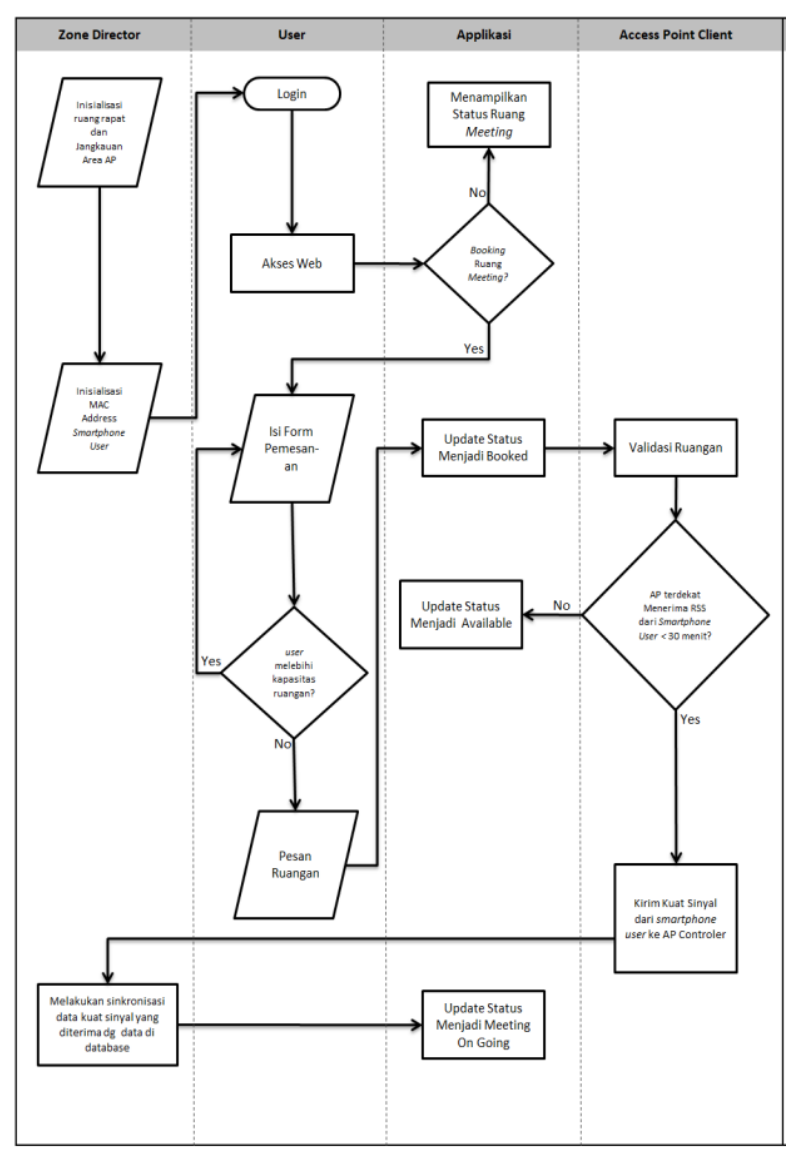

Gambar 4. Diagram Alur Sistem Ketersedian Ruangan

\subsection{Inisialisasi Ruangan}

Area yang akan dilakukan inisialisasi yaitu area pada lantai 2 (dua). Denah lokasi untuk area pada lantai 2 dapat dilihat pada gambar.5. Pada lantai dua terpasang lima access point untuk mencakup tiga area (biru, merah, dan kuning) dan satu access point untuk area hijau (project). Pada area biru terpasang dua access point, pada area merah terpasang satu access point, dan pada area kuning terpasang dua access point. Sedangkan, pada area hijau (project) terpasang satu access point. Access point yang sudah terpasang, selanjutnya dilakukan diinisialisasi MAC address access point pada zone director (access point controller), agar smartphone dapat terkoneksi ke sinyal wifi.

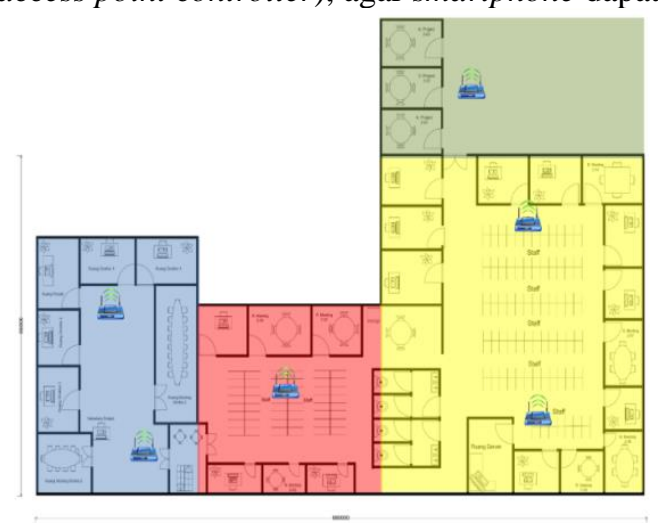

Gambar 5 Denah Lokasi Ruangan Lantai 2 


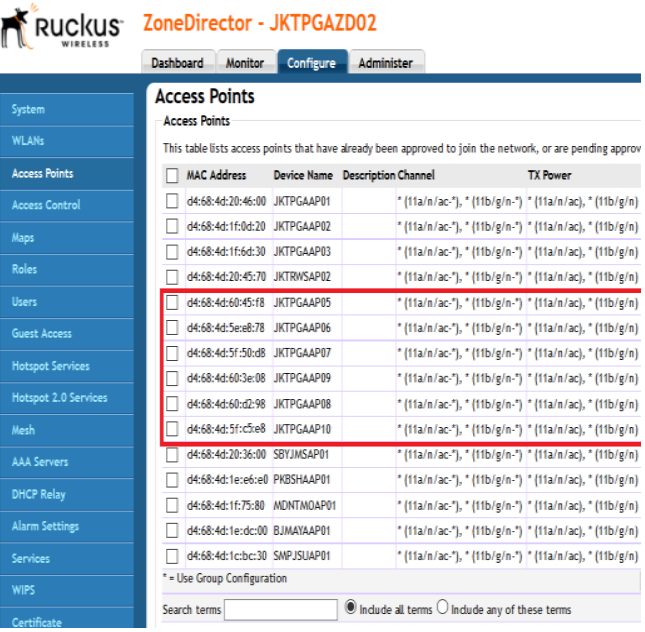

Gambar 6 Hasil inisialisasi access point pada zone director

Access point yang terpasang pada lantai dua yaitu access point JKTPGA06 sampai dengan JKTPGA10. Dengan MAC address access point yang berbeda pada setiap access point. Daftar MAC address access point di lantai 2, dapat dilihat pada gambar.6 dan tabel.4.

Tabel. 4 Inisialisasi access point pada zone director

\begin{tabular}{|c|c|}
\hline Access Point & MAC Address \\
\hline JKTPGA05 & $\mathrm{d} 4: 68: 4 \mathrm{~d}: 60: 45: f 8$ \\
\hline JKTPGA06 & $\mathrm{d} 4: 68: 4 \mathrm{~d}: 5 \mathrm{e}: \mathrm{e} 8: 78$ \\
\hline JKTPGA07 & $\mathrm{d} 4: 68: 4 \mathrm{~d}: 5 \mathrm{f}: 50: \mathrm{d} 8$ \\
\hline JKTPGA08 & $\mathrm{d} 4: 68: 4 \mathrm{~d}: 60: 3 \mathrm{e}: 08$ \\
\hline JKTPGA09 & $\mathrm{d} 4: 68: 4 \mathrm{~d}: 60: \mathrm{d} 2: 98$ \\
\hline JKTPGA10 & $\mathrm{d} 4: 68: 4 \mathrm{~d}: 5 \mathrm{f}: \mathrm{c} 5: \mathrm{e} 8$ \\
\hline
\end{tabular}

\subsection{Inisialisasi Jangkauan Access Point pada Ruangan}

Untuk mengetahui cakupan area access point pada masing-masing ruangan dilakukan dengan menentukan jangkauan access point untuk menjangkau ruangan. Ruangan yang akan dilakukan inisialisasi yaitu semua ruangan yang berada dilantai dua. Ruangan yang akan dilakukan inisialisasi jangkauan access point pada skripsi ini yaitu ruangan 2-04. Proses inisialisai ini dilakukan untuk mengetahui kuat sinyal yang dijangkau oleh setiap acceess point terhadap ruangan. Kuat sinyal yang diterima oleh ruangan akan berbeda-beda dari setiap access point. Hasil proses inisialisai jangkaun setiap access point selanjutnya disimpan pada server database.

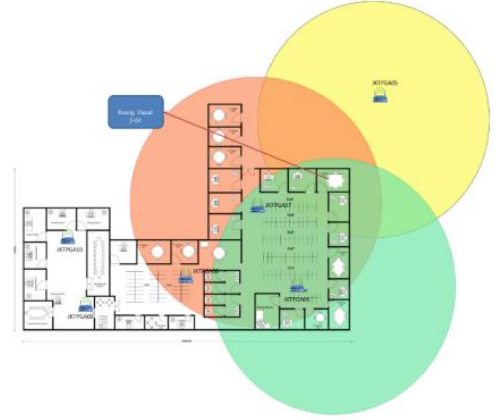

Gambar . 7 Coverage access point pada ruangan 2-04 
Pada gambar.7 area ruangan 2-04 dijangkau oleh tiga access point terdekat yaitu acces point JKTPGA05, access point JKTPGA06, dan access point JKTPGA07.

\subsection{Inisialisasi MAC Address Smartphone}

MAC address smartphone diinisialisasi pada access point controller (Zone Director). Inisialisasi MAC address smartphone dilakukan untuk proses validasi ruangan. Pada saat memesan ruangan user mendaftarkan NRP (Nomor Register Pegawai) yang akan memakai ruangan, kemudian akan dilakukan validasi oleh access point dengan menerima sinyal dari smartphone dan MAC address smartphone yang sudah diinisialisasi, hanya user yang sudah terinisialisasi MAC address nya yang dapat terkoneksi ke jaringan wifi. Inisialisasi MAC address terlihat pada gambar 8 .

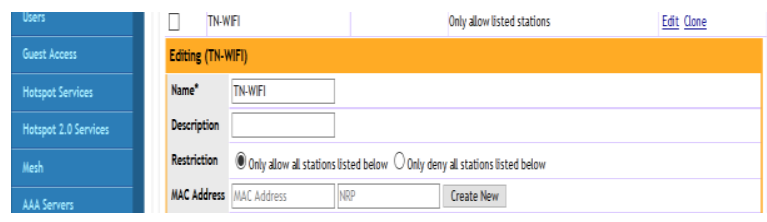

Gambar 8 Inisialisiasi MAC Address smartphone

Zone director dapat menampung hingga 500 MAC address smartphone. Smartphone akan otomatis terkoneksi melalui jaringan TN-WIFI saat berada di area kantor.

\subsection{Proses Validasi Ruangan}

Validasi dilakukan menggunakan pendeteksian kuat sinyal yang diterima oleh smartphone user dari tiga access point terdekat. Proses validasi ruangan dapat dilihat pada gambar 9. Berdasarkan pada gambar 9 access point JKTPGA05, JKTPGA06, dan JKTPGA07 memiliki kuat sinyal besar dan jarak yang dekat terhadap ruangan 2-04 dengan penerimaan besaran kuat sinyal yang berbeda dari masing-masing access point. Pada saat user (ditunjukan dengan bentuk kotak) memasuki ruangan, smartphone user menerima kuat sinyal dari 3 access point terdekat (JKTPGA05, JKTPGA06, dan JKTPGA07). Smartphone user secara otomatis langsung terhubung ke access point JKTPGA07 karena access point tersebut memiliki kuat sinyal dan jarak paling dekat dengan posisi user saat ini.

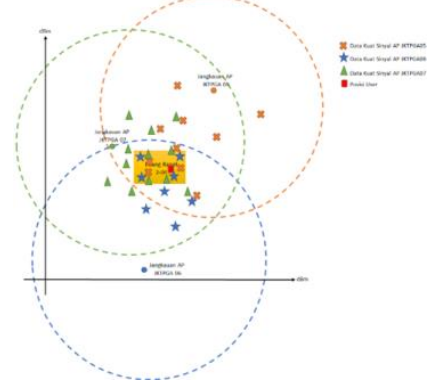

Gambar 9. Proses Validasi Ruangan

Smartphone user mengirim kuat sinyal yang diterima dari access point tetangga (access point JKTPGA05, dan access point JKTPGA06) yang jarak dan kuat sinyalnya dekat dengan dan access point tetangga mengirimkan informasi kuat sinyal yang diterima ke access point controller. access point controller melakukan sinkronisasi data terhadap jangkauan kuat sinyal pada ruangan yang sudah diinisialisasi.

\section{Hasil Dan Pembahasan}

\subsection{Walk Test Jangkauan Access Point Pada Ruangan}

Pada tahap ini, walk test jangkauan access point dilakukan pada setiap ruangan pertemuan dengan menggunakan aplikasi wifi analyzer dan SSID (Service Set Identifier) TN-WIFI untuk mengetahui kuat sinyal yang dijangkau oleh setiap access point yang diterima oleh setiap ruangan. Pada pengujian skripsi ini, Ruangan yang akan dilakukan walk test yaitu ruangan 2-04 yang berada dilantai dua. Berikut sinyal yang didapatkan dari hasil walk test RSS menggunakan aplikasi wifi analyzer. 
1. Access point JKTPGA05, access point ini memiliki mac address $\mathrm{d} 4: 68: 4 \mathrm{~d}: 60: 45: f 8$. Kuat sinyal yang didapat pada area ruangan 2-04 dapat dilihat pada gambar 10.

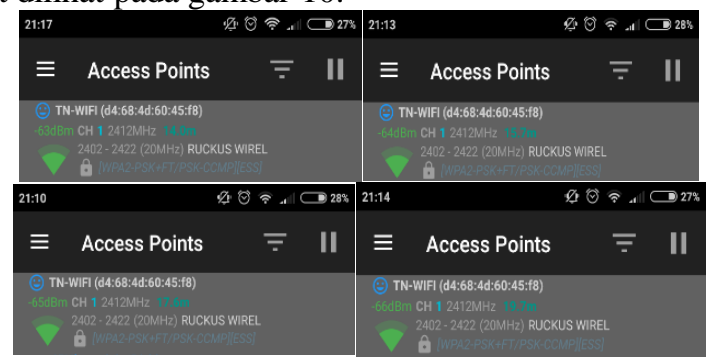

Gambar 10. Kuat sinyal ruangan 2-04 pada access point JKTPGA05

Berdasarkan pada Gambar 10. kuat sinyal yang diterima oleh ruangan 2-04 dari access point JKTPGA05 yaitu: $-63 \mathrm{dBm},-64 \mathrm{dBm},-65 \mathrm{dBm}$, dan $-66 \mathrm{dBm}$.

2. Access point JKTPGA06, access point ini memiliki mac address $\mathrm{d} 4: 68: 4 \mathrm{~d}: 5 \mathrm{e}: \mathrm{e} 8: 78$. Kuat sinyal yang didapat pada area ruangan 2-04 dapat dilihat pada gambar 11.

3. Berdasarkan pada Gambar 11. kuat sinyal yang diterima oleh ruangan 2-04 dari access point JKTPGA06 yaitu: $-59 \mathrm{dBm},-60 \mathrm{dBm},-62 \mathrm{dBm}$, dan $-63 \mathrm{dBm}$.

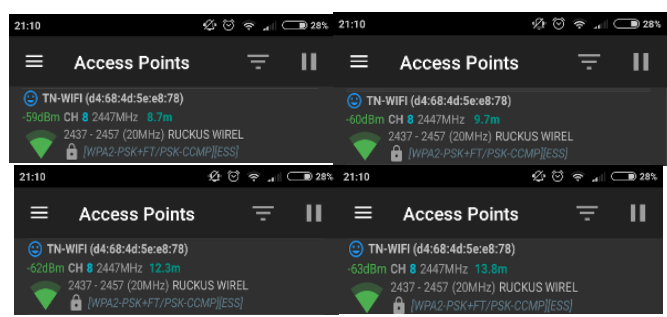

Gambar 11. Kuat sinyal ruangan 2-04 pada access point JKTPGA06

4. Access point JKTPGA07, access point ini memiliki mac address $\mathrm{d} 4: 68: 4 \mathrm{~d}: 5 \mathrm{f}: 50: \mathrm{d} 8$. Kuat sinyal yang didapat pada area ruangan 2-04 dapat dilihat pada gambar 12.

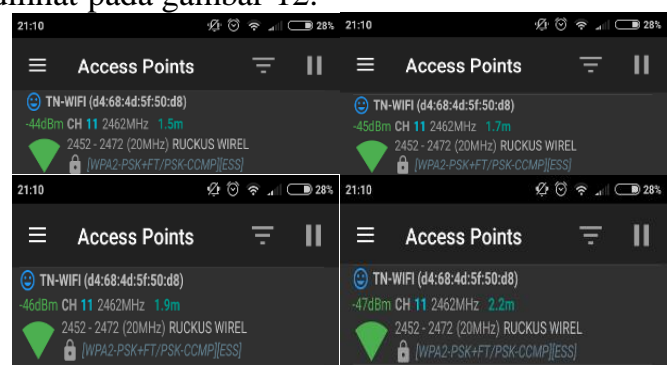

Gambar 12. Kuat sinyal ruangan 2-04 pada access point JKTPGA07

Berdasarkan pada Gambar 4.2 kuat sinyal yang diterima oleh ruangan 2-04 dari access point JKTPGA07 yaitu: $-44 \mathrm{dBm},-45 \mathrm{dBm},-46 \mathrm{dBm}$, dan $\quad-47 \mathrm{dBm}$. Berdasarkan hasil walk test jangkauan access point terhadap ruangan pada gambar 10, 11, dan 12 access point dengan kuat sinyal paling besar yaitu access point JKTPGA07. Smartphone user akan otomatis terkoneksi ke access point JKTPGA07.

\subsection{Pemesanan Ruangan}

Pada tahap ini, dilakukan pengujian pemesanan ruangan melalui aplikasi internal yang dapat diakses melalui web dengan browser chome atau mozilla firefox dengan url traknus.roombooking. Seperti pada gambar 13. 


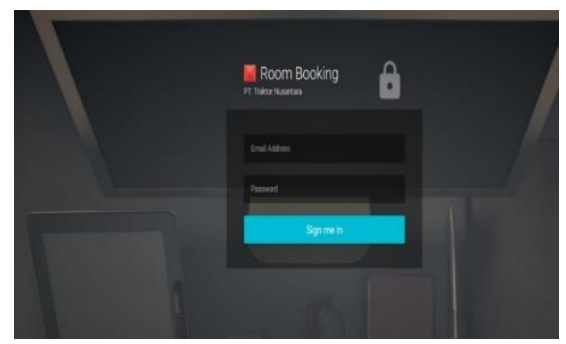

Gambar 13. Halaman login ruangan

Pada sistem ini, user dapat melihat status ketersediaan ruangan, dan melakukan pemesanan ruangan. User dapat melihat status ketersediaan ruangan dengan tampilan list view ataupun maps view. Untuk melihat status ketersediaan ruangan atau melakukan pemesanan ruangan, user melakukan login terlebih dahulu pada aplikasi internal. User selanjutnya melakukan pemesanan ruangan dengan mengisi form pemesanan ruangan. Pada aplikasi terdapat menu Booking Room dan View Room. Menu booking room digunakan untuk mengisi form pemesanan ruangan, sedangkan menu view room digunakan untuk melihat list ruangan yang tersedia. Terdapat tiga status untuk mengidentifikasi ketersediaan ruangan yaitu, status available, booked, dan nonavailable. Status available diberikan utnuk ruangan yang masih tersedia, status booked diberikan untuk ruangan yang sudah dipesan oleh user, dan status non available diberikan untuk ruangan yang sedang digunakan pertemuan oleh $u s e r$.

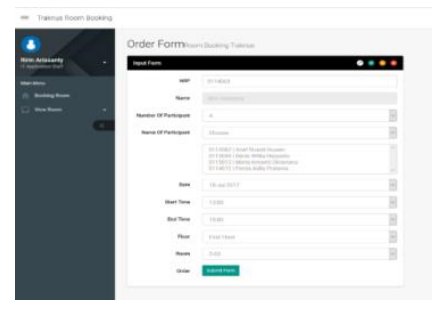

Gambar 14 Contoh Pemesanan Ruangan

Pada form pemesanan ruangan (gambar 14), user diminta untuk memasukan nomor karyawan (NRP) pemesan, nama pemesan, jumlah peserta, list nama peserta pertemuan, tanggal dilaksanakannya, jam mulai dan jam selesai dilaksanakannya, lantai ruangan yang akan dipesan, dan ruangan yang akan dipesan. Apabila form sudah terisi sistem akan mengubah status ruangan menjadi booked, dan selanjutnya akan di validasai pada tanggal dan jam yang sudah dipesan. Status ruangan dapat dilihat pada gambar 15

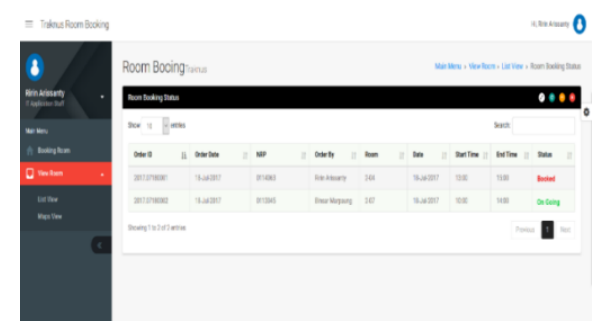

Gambar 15. List view status ruangan

\subsection{Validasi Ruangan}

Pada tahap ini, dilakukan pengujian validasi ruangan yang sudah dipesan sebelum melakukan kegiatan. Proses validasi dilakukan pada access point controller (zone director) dengan menggunakan metode K-NN dan melakukan pendeteksian kuat sinyal yang diterima oleh smarphone user yang sudah didaftarkan pada form pemesanan ruangan melalui aplikasi room booking. Proses validasi ruangan menggunakan metode K-NN yang dapat dilihat pada gambar 16. 


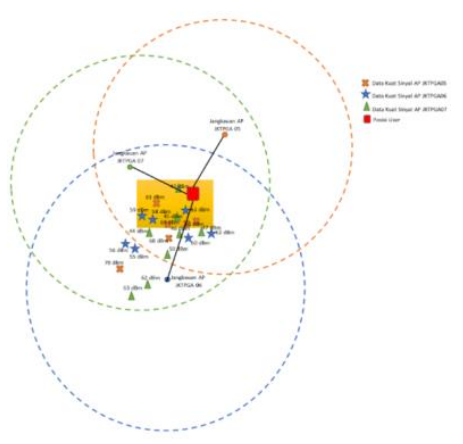

Gambar 16. Validasi ruangan dengan metode K-NN

Berdasarkan data klasifikasi kuat sinyal hasil walk test pada sub bab 4.1, kuat sinyal yang diterima oleh ruangan 204 dari access point JKTPGA05, JKTPGA06, dan JKTPGA07 dapat dilihat pada tabel 5

Tabel 5. Data hasil walk test access point pada ruang
\begin{tabular}{|l|l|l|}
\hline JKTPGA 05 & JKTPGA06 & JK TPGA 07 \\
\hline$-63 \mathrm{dBm}$ & $-59 \mathrm{dBm}$ & $-44 \mathrm{dBm}$ \\
\hline$-64 \mathrm{dBm}$ & $-60 \mathrm{dBm}$ & $-45 \mathrm{dBm}$ \\
\hline$-65 \mathrm{dBm}$ & $-62 \mathrm{dBm}$ & $-46 \mathrm{dBm}$ \\
\hline$-66 \mathrm{dBm}$ & $-63 \mathrm{dBm}$ & $-47 \mathrm{dBm}$ \\
\hline
\end{tabular}

Berdasarkan klasifikasi kuat sinyal pada bab sebelumnya, pada saat user berada pada titik merah (gambar 16) $6 \mathrm{~K}$ kuat sinyal terbesar semuanya berada didalam ruangan 2-04, sehingga dengan menggunakan kategori mayoritas pada metode K-NN posisi user berada didalam ruangan. Dengan demikian, access point controller memberikan informasi kepada aplikasi ruangan bahwa ruangan 2-04 telah terisi oleh user sehingga aplikasi ruangan mengubah status ruangan menjadi on going.

\subsection{Pengujian Ketersediaan Ruangan Pada Aplikasi}

Pada tahap ini, dilakukan pengujian ketersediaan ruangan melalui sistem aplikasi room booking. Pada sistem ini sebelumnya dilakukan proses order ruangan terlebih dahulu oleh user yang akan menggunakan ruangan seperti yang sudah dilakukan pada pengujian poin 4.2. Sistem akan menampilkan ruangan yang tersedia melalui menu maps view. Pada gambar 17. terdapat tujuh ruangan yang tersedia dengan warna indikator kuning, satu ruangan yang sudah dibooking (warna indikator merah), dan satu ruangan yang sedang digunakan (warna indicator hijau).

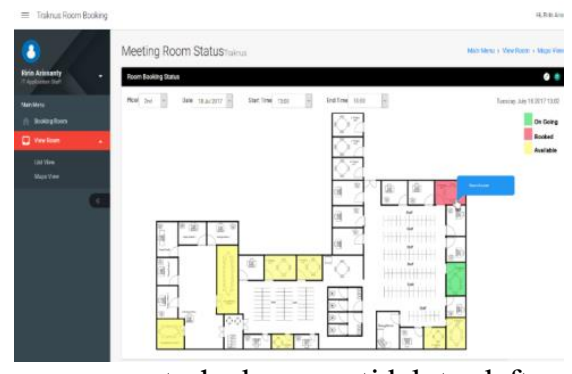

Gambar 17 Status ruangan terhadap user tidak terdaftar pada form order

Pada gambar 17 sistem melakukan validasi terhadap ruangan yang sudah dipesan dengan mengubah status ruangan 2-04 menjadi warna hijau (on going). Saat kursor diarahkan ke ruangan, sistem akan memberikan informasi user yang sedang berada dalam ruangan. Apabila didalam ruangan 2-04 ada user selain user yang didaftarkan pada form pemesanan ruangan, sistem tidak akan mengubah status ruangan. Batas waktu maksimal user masuk ruangan yaitu 30 menit dari waktu pada form pemesanan ruangan. Apabila dalam 30 menit user 
terdaftar tidak ada diruangan yang sudah dipesan, sistem secara otomatis akan mengubah status ruangan menjadi available.

\section{Kesimpulan}

Berdasarkan pembahasan maka dapat disimpulkan sebagai berikut:

1. Sistem dapat memberikan informasi terhadap status ruangan yang kosong dengan melakukan validasi terhadap kuat sinyal yang diterima oleh smartphone dari 3 access point terdekat yaitu access point JKTPGA05, JKTPGA06, dan JKTPGA07 menggunakan metode K-NN. Status ruangan yang kosong dapat dilihat melalui aplikasi web room booking pada situs traknus.roombooking.

2. Smartphone terkoneksi pada access point dengan kuat sinyal yang paling besar dengan range $-45 \mathrm{dBm}$ sampai $50 \mathrm{dBm}$.

3. Sistem melakukan validasi terhadap ruangan selama 30 menit dari waktu pemesanan yang sudah diisi pada form pemesanan ruangan.

\section{Daftar Pustaka}

[1] Lukito, Yuan. Perbandingan Metode-Metode Klasifikasi Untuk Indoor Positioning System.Yogyakarta: Universitas Kristen Duta Wacana, 2015. Skripsi.

[2] Anonim. (n.d).). Pengertian dan Fungsi WiFi. Retrived Mei 21, 2016, from wifi.id: https://wifi.id/news/157/Pengertian+dan+Fungsi+WiFi.

[3] Tito. Standar Protokol Jaringan Wireless (Wifi) IEEE 802.11. Retrived Mei 6, 2016, from www.nusa.net.id: https://www.nusa.net.id/article/standar-protokol-jaringan-wireless-ieee-802-11/.

[4] Srirahayu, Penjelasan Access Point. Retrived Februari 12, 2016, from blog.unnes.ac.id: http://blog.unnes.ac.id/srirahayu/2016/02/12/penjelasan-access-point-ap/

[5] Sanha. Pengertian Access Point dan Fungsinya. Retrived December 6, 2015, from www.wirelessmode.net: http://www.wirelessmode.net/ pengertian-access-point-dan-fungsinya.html.

[6] Sukma, Alfian. K-Nearest Neighbor. Surabaya: Universitas Airlangga, 2014. Skripsi.

[7] Micro, Andi. 2012. Dasar-Dasar Jaringan Komputer. Clear OS Indonesia Retrived September 8, 2017, from https://www.scribd.com/document/150032502/eBook-Teknisi-Jaringan-Komputer-Lengkap.

[8] Alamsyah, Bambang Nur. Optimalisasi Kualitas Pengiriman dan Penerimaan Gambar pada Video Conference. Jakarta: Institute Sain dan Teknologi Nasional, 2015. Skripsi.

[9] Rizky, Ichsan Parama Putra. Sistem Pendeteksian Posisi dalam Ruangan Menggunakan Kekuatan Sinyal WiFi dengan Penerapan Algoritma Cluster Filtered KNN. Surabaya: Institu Teknologi Sepuluh Nopember, 2013. Skripsi.

[10] Zhuro. Jenis Tipe Mode Wireless. Retrived Januari 12, 2015, from zhuro.wordpress.com: https://zhuro.wordpress.com/2015/01/12/jenis-tipe-mode-wireless/

[11] Anto. Berapa Jauh Daya Jangkau Sinyal Wifi $2.4 \mathrm{GHz}$ dan 5 GHz. Retrived Maret 24, 2014, from www.norisanto.com:http://www.norisanto.com/wireless/berapa-jauh-daya-jangkau-sinyal-wi-fi-2-4-ghzdan-5-ghzl

[12] Alfredo. Autentikasi, Asosiasi dan Roaming Pada Jaringan Wireless. Retrived Mei 15, 2012, from alfredo.wordpress.com: https://alfredoeblog.wordpress.com/2012/05/15/autentikasi-asosiasi-dan-roamingpada-jaringan-wireless/

[13] F. Faisal, R. Munadi, and S. Syahrial, “Analisis Perbandingan Performansi Transmisi Video Dengan Unicast Pada Wlan Ieee 802.11 ac," J. Nas. Komputasi dan Teknol. Inf., vol. 1, no. 2, 2018.

[14] T. Hidayat, Z. Zulfan, M. Munawir, and S. Susmanto, "Perbandingan Metode Antrian Paket HTB dan EDCA Untuk Layanan Multimedia Pada WLAN IEEE 802.11 n," J. Nas. Komputasi dan Teknol. Inf., vol. 3, no. 2, pp. 132-143, 2020. 